$\mathcal{B} \mathcal{T} \mathcal{P} \mathcal{S}$

Brazilian Transportation

Planning Society
Journal of Transport Literature

Vol. 7, n. 1, pp. 127-146, Jan 2013

Reviews \& Essays
JTL | RELIT

www.transport-literature.org ISSN 2238-1031

\title{
Demanda aeroportuária de Manaus e sua influência para o setor de turismo da região
}

[Demand of Manaus airport and its influence on the tourism sector in the region]

\author{
Viviane Adriano Falcão*
}

Instituto Tecnológico de Aeronáutica (ITA), Brazil

Submitted 3 Jul 2011; received in revised form 12 Dec 2011; accepted 26 Jan 2012

\begin{abstract}
Resumo
O presente artigo tem como objetivo fazer um estudo da demanda de passageiros pelo aeroporto Eduardo Gomes de Manaus e analisar a influência para o setor de turismo. A partir deste estudo, fez-se uma previsão do crescimento orgânico da demanda de passageiros para o ano de 2014. Para prever a demanda, foram utilizadas ferramentas econométricas com o objetivo de desenvolver modelos de previsão da demanda de passageiros. Os resultados obtidos mostram que a demanda total de passageiros projetada para 2014 é de mais de 3,8 milhões, bem acima da capacidade atual de 2,5 milhões de passageiros anuais. Para o setor de turismo, o fluxo da região chegará em 2014 com uma demanda anual de 59 mil turistas. Esta demanda mais que duplica a quantidade de turistas que existe atualmente. Esses resultados demonstram a necessidade de um investimento na infraestrutura do aeroporto Internacional Eduardo Gomes, bem como na infraestrutura turística.
\end{abstract}

Palavras-Chave: aeroporto de Manaus; econometria; estudo de demanda; infraestrutura aeroportuária; turismo.

\section{Abstract}

This article purpose to study the demand of passengers through the airport in Manaus Eduardo Gomes and analyze that's influence on the tourism sector. On the basis of this study, could provide the organic growth of passenger demand for the year 2014. To be able to forecast demand, were used econometric tools, it developed models for forecasting passenger demand. The results show that the total demand of passengers forecast for 2014 is more than 3.8 million, well above the current capacity of 2.5 million passengers annually. To the tourism industry in the region the flow will arrive in 2014 with an annual demand of 59 000 tourists. This demand more than doubles the number of tourists that currently exists. These results demonstrate the necessity to invest in infrastructure for Eduardo Gomes International Airport, as well as in tourism infrastructure.

Key words: Manaus airport; econometrics; demand study; airport infrastructure; tourism..

*Email: viviane.falcao@yahoo.com.br.

\section{Recommended Citation}

Falcão, V. A. (2013) Demanda aeroportuária de Manaus e sua influência para o setor de turismo da região. Journal of Transport Literature, vol. 7, n. 1, pp. 127-146.

- JTL/RELIT is a fully electronic, peer-reviewed, open access, international journal focused on emerging transport markets and published by BPTS - Brazilian Transport Planning Society. Website www.transport-literature.org. ISSN 2238-1031.

This paper is downloadable at www.transport-literature.org/open-access. 


\section{Introdução}

O objetivo central do artigo é fazer uma projeção da demanda, doméstica e internacional, para 2014, no aeroporto Internacional Eduardo Gomes em Manaus e analisar a influência para o setor de turismo. A metodologia utilizada tem como base conceitos da econometria, principalmente a regressão linear, seguida de um modelo de previsão de demanda.

Ultimamente o tema "Infraestrutura aeroportuária brasileira" vem sendo pauta de grandes discussões no âmbito nacional, isso se deve principalmente ao fato da aproximação da Copa do Mundo de 2014. A cidade de Manaus foi eleita pela Federação Internacional de Futebol Associado (FIFA) como uma das cidades sede da copa do mundo de 2014, representando assim a região amazônica. Este fato colocará a capital Amazonense em evidência pelos próximos anos e sob constante pressão para entregar os projetos de infraestrutura necessários para a realização do mundial. Dentre esses projetos, encontra-se a reforma e ampliação do terminal de passageiros do aeroporto internacional Eduardo Gomes que teve edital publicado em 25 de maio de 2011. O início das obras está programado para novembro de 2011 e tem conclusão prevista para dezembro de 2013, segundo o site da INFRAERO. Esta reforma tem o objetivo de elevar sua capacidade de 2,5 milhões de passageiros anuais para 5 milhões.

O crescimento econômico do Brasil e o consequente aumento do Produto Interno Bruto contribuem bastante para as altas taxas de crescimento da demanda pelo transporte aéreo. A tendência no Brasil é que a intensidade do uso do modal aéreo se aproxime à intensidade de viagens em países desenvolvidos, ou seja, que passe de 0,3 para 0,7 viagem/habitante por ano, conforme Relatório Consolidado (2010). Esse aumento de passageiro sem dúvidas tem uma relação direta com o fluxo de turistas no país.

Para Andrade apud Bessa e Batista (2010), "o desenvolvimento da aviação comercial pode ser considerado tanto causa quanto efeito da expansão turística”. Palhares apud Bessa e Batista (2010) o considera não só como facilitador, mas como "catalisador, integrador e multiplicador" da indústria do turismo, pois há uma integração para contribuir com a demanda turística tanto nacional quanto internacional. Nesse contexto, percebe-se que o aeroporto se torna o portão de entrada de uma cidade e, portanto indispensável para o turismo. 
Hoje no Brasil o setor de turismo representa 3,6\% do PIB nacional, podendo chegar em 2020 até a $6 \%$ do PIB nacional, ou seja, quase duplicar o fluxo de turistas pelo país. Na região Amazônica, o setor de turismo representa 2,1\% do PIB do estado. Em teoria no estado do Amazonas, podem ser observados os dois tipos de turismo, o turismo em geral e o ecoturismo. Conforme dados do Estudo de Demanda Turística (2010) cerca de 67\% dos turistas que vão a Manaus tem como objetivo de lazer fazer ecoturismo na região.

Os resultados obtidos apontam que a demanda total de passageiros projetada para 2014 é de mais de 3,8 milhões, bem acima da capacidade atual de 2,5 milhões de passageiros anuais. Para o setor de turismo, o fluxo da região chegará em 2014 com uma demanda anual de 59 mil turistas. Esta demanda mais que duplica a quantidade de turistas que existe atualmente. Esses resultados demonstram a necessidade de um investimento na infraestrutura do aeroporto Internacional Eduardo Gomes, bem como na infraestrutura turística.

Os resultados obtidos apontam que a demanda total de passageiros projetada para 2014 é de mais de 3,8 milhões, bem acima da capacidade atual de 2,5 milhões de passageiros anuais. Para o setor de turismo, o fluxo da região chegará em 2014 com uma demanda anual de 59 mil turistas. Esta demanda mais que duplica a quantidade de turistas que existe atualmente. Esses resultados demonstram a necessidade de um investimento na infraestrutura do aeroporto Internacional Eduardo Gomes, bem como na infraestrutura turística.

Esse estudo de demanda pode auxiliar os tomadores de decisão a definir as prioridades de investimento para o aeroporto de Manaus, bem como para a infraestrutura turística da região. Esse artigo está estruturado em cinco seções, além desta introdutória. A segunda seção faz uma definição do turismo e do ecoturismo além de uma breve consideração da situação na região Amazônica. A terceira seção apresenta o aeroporto e suas principais características. $\mathrm{Na}$ quarta seção será abordado o estudo de demanda, e está dividido em três subseções que são a apresentação da base de dados, o estudo econométrico, bem como o modelo e os seus resultados, e finalmente a previsão da demanda. Por fim, a seção cinco apresentará as conclusões deste trabalho. 


\section{Turismo na região}

Segundo Francisco de la Torre apud Bessa e Batista (2010) pode-se definir turismo como sendo "um fenômeno social que consiste no deslocamento voluntário e temporário de indivíduos ou grupos de pessoas que, fundamentalmente por motivos de recreação, descanso, cultura ou saúde, saem do seu local de residência habitual para outro, no qual não exercem nenhuma atividade lucrativa nem remunerada, gerando múltiplas inter-relações de importância social, econômica e cultural."

O International Ecotourism Society (2011) define o ecoturismo como "A viagem responsável para áreas naturais de uma maneira em que se conserva o meio ambiente e promove-se o bemestar da população local." Neleman (2009) apresenta uma definição um pouco mais elaborada do ecoturismo, ele considera que o ecoturismo é uma viagem para áreas naturais consideradas intocadas e nao contaminadas cujo objetivo principal é estudar, admirar e desfrutar do meio ambiente, bem como das manifestações culturais existentes nesta região.

Segundo dados do anuário estatístico do Ministério do Turismo (2011) somente 0,5\% dos turistas estrangeiros chegam por Manaus e cujo destino final deva ser Manaus ou alguma cidade no estado do Amazonas. Turistas esses em sua maioria norte americanos. Acredita-se que essa demanda norte americana por Manaus acontece principalmente por conta da existência do voo direto entre Manaus e Miami. Pode-se confirmar a procura estrangeira por Manaus ao se analisar os dados do Estudo da Demanda Turística (2010) mais especificamente os dados do perfil de turista onde o destino mais visitado é Manaus, quase 34\% desses turistas estrangeiros tem o país de residência situado na Europa, essa porcentagem equivale a demanda dos norte americanos por Manaus. Vale ressaltar que os norte americanos podem ser considerados os principais turistas estrangeiros de Manaus, com um porcentagem de em média $34,7 \%$.

Hoje no Brasil o setor de turismo representa 3,6\% do PIB, podendo chegar em 2020 até a 6\% do PIB, ou seja, quase duplicar a demanda turística no país. Na região Amazônica, o setor de turismo representa 2,1\% do PIB do estado. Em teoria no estado do Amazonas pode ser observado dois tipos de turismo, o turismo em geral e o ecoturismo. Porém ainda há muitos desafios a serem vencidos para que o turismo ocupe um lugar importante na economia da região, entre eles: pouca acessibilidade, falta de infraestrutura básica (saneamento), falta de 
infraestrutura turística (sinalização, centros de recepção e de informação ao turismo), além, e principalmente, problemas de falta de infraestrutura de transportes, em todos os modais.

Para Bessa e Batista (2010) a expansão turística pode ser considerada tanto causa quanto efeito do desenvolvimento da aviação comercial. Palhares apud Bessa e Batista (2010) o considera não só como facilitador, mas como "catalisador, integrador e multiplicador" da indústria do turismo, pois há uma integração para contribuir com a demanda turística tanto nacional quanto internacional. Nesse contexto, percebe-se que o aeroporto se torna o portão de entrada de uma cidade e portanto indispensável para o desenvolvimento do turismo.

\section{Análise do Aeroporto de Manaus}

O aeroporto Eduardo Gomes está localizado na cidade mais populosa da região amazônica, com 1,8 milhões de habitantes, segundo dados do IBGE (2011), é o principal aeroporto do estado do Amazonas. Esta região é marcada pela pequena quantidade de alternativas de transporte rodoviário, o que obriga seus habitantes e visitantes a utilizarem outros modais de transportes, tais como o hidroviário e o aeroviário.

Na Zona Franca de Manaus, existe uma grande movimentação de mercadorias, isso acontece pelo fato que, nessa região as empresas gozam de incentivos fiscais especiais. Esses incentivos fazem parte de um plano geoeconômico para impulsionar o desenvolvimento da região norte do Brasil conforme definição do Site Infoescola (2011). Ela foi criada em 1967 com o intuito de promover o desenvolvimento industrial da região, criando, portanto, a necessidade de escoamento da produção para outras localidades. A Zona Franca teve sua existência prorrogada até 2023. Atualmente engloba 508 empresas e tem um faturamento anual de cerca de US\$27 bilhões (2007), respondendo por mais de 50\% do PIB amazonense. O aeroporto é a única alternativa rápida existente para realizar o escoamento da produção. Outra alternativa é o porto flutuante da cidade, mas o uso da hidrovia demanda um tempo muito maior para realizar o transporte de mercadorias.

A economia da região é movida principalmente pelas atividades do polo industrial de Manaus, mas também por algumas iniciativas de agronegócios no estado do Amazonas. A capital amazonense possue o sexto maior PIB municipal brasileiro segundo o IBGE, totalizando mais 
de 47,4 bilhões de reais ano. O setor de serviços também tem uma parcela importante na economia da cidade, representando mais de $40 \%$ do total do PIB de Manaus. O PIB de Manaus representa mais de $80 \%$ do produto interno bruto do estado do Amazonas.

\subsection{Características do aeroporto}

O aeroporto internacional de Manaus é a porta de entrada para a Amazônia brasileira, tendo sido inaugurado em 1976 para atender à demanda por transporte aéreo da época. O modal aéreo, onde o aeroporto é o elo principal, é muito importante para a cidade de Manaus, devido às características físicas da região. Além da demanda de passageiros, o transporte de carga também é muito importante para a região, principalmente pela presença da Zona Franca de Manaus, que traz como resultado um maior dinamismo industrial para a região metropolitana. Durante seus primeiros anos de funcionamento chegou a ser considerado o aeroporto mais moderno do país, sendo o primeiro a ser equipado com fingers (passarelas móveis para embarque de passageiros).

Hoje, o aeroporto conta com capacidade para movimentar 2,5 milhões de passageiros por ano e já opera próximo a este limite, tendo transportado 2,3 milhões de passageiros no ano de 2009. A INFRAERO, empresa estatal que administra o aeroporto, já apresentou planos para promover a reestruturação do terminal de passageiros 1 a fim de aumentar sua capacidade para 5 milhões de passageiros anuais. O processo licitatório de escolha da construtora foi iniciado e a obra tem uma previsão de conclusão até janeiro de 2014.

O aeroporto Eduardo Gomes conta com uma única pista de 2700 por 45 metros, com dois terminais de passageiros, um para atender a aviação regular (nacional e internacional) e o outro a aviação regional. No tocante a infraestrutura para a carga ele dispõe de um complexo de logística de carga, que foi implantado em três etapas, sendo o Terminal de Logística 1 inaugurado em 1976, o Terminal de Logística 2 em 1980 e o Terminal de Logística 3 em 2004, segundo dados da INFRAERO (2011). 


\subsection{O aeroporto em números}

A partir das informações disponíveis no site da ANAC (2011), via relatório HOTRAN, podese confirmar o aeroporto de Manaus tem realmente uma grande importância na movimentação de cargas. Cerca de $60 \%$ do seu movimento tem fins de escoamento de mercadoria. Segundo a Figura 1, que apresenta a distribuição dos movimentos de aeronaves regulares no aeroporto de Manaus ao longo do dia. Em termos de passageiros o aeroporto tem um maior movimento às 16:00 horas e em termos de carga às 9:00 horas.

Atualmente existem 17 companhias aéreas operando no aeroporto de Manaus, sendo 12 dessas empresas exclusivamente cargueiras. Companhias aéreas de diferentes nacionalidades fazem o transporte de cargas do Brasil para países vizinhos do continente Sul-Americano, bem como para os Estados Unidos da América.

$\mathrm{Na}$ análise dos números para o transporte de passageiros domésticos, percebe-se a grande importância regional do aeroporto, com cerca de $34 \%$ dos voos operados pela TRIP. O restante dos voos domésticos nacionais ficam divididos entre a GOL e TAM, cada uma com cerca de $31 \%$, seguidas pela AZUL e a COPA, com $2 \%$ cada. Existe somente dois destinos internacionais diários saindo do aeroporto de Manaus, o primeiro é Miami, operado pela TAM, e o outro é Panamá, operado pela COPA.

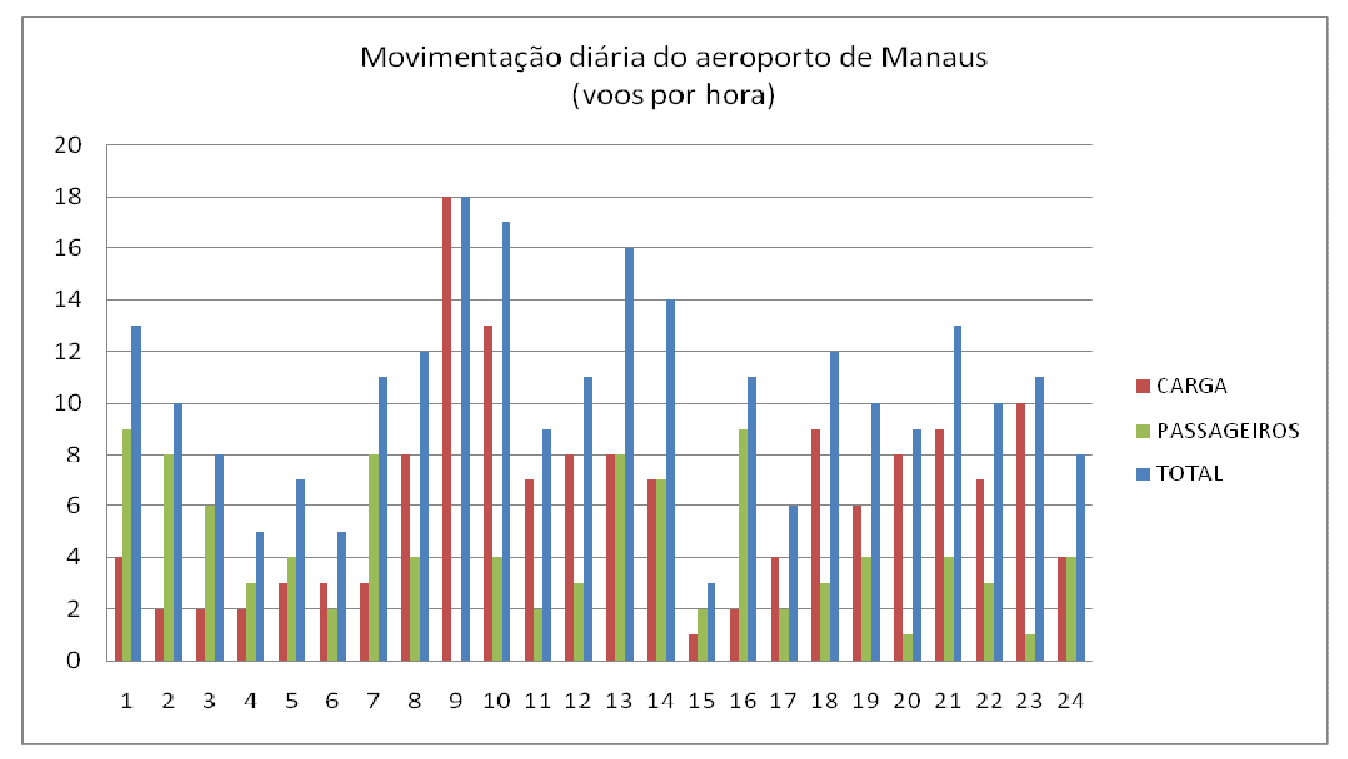

Figura 1 - Movimento de aeronaves realizadas no aeroporto de Manaus. Fonte: ANAC 


\subsection{Análise da malha}

As rotas operadas podem ser divididas em rotas regionais, nacionais e internacionais. As rotas internacionais com origem ou destino no aeroporto de Manaus são exibidas na figura 2. É possível notar que não há conexão com outros continentes que não o americano. Isso se deve ao fato de que os principais destinos dos produtos do polo industrial de Manaus é o mercado norte-americano e o Mercosul, além do mercado doméstico.

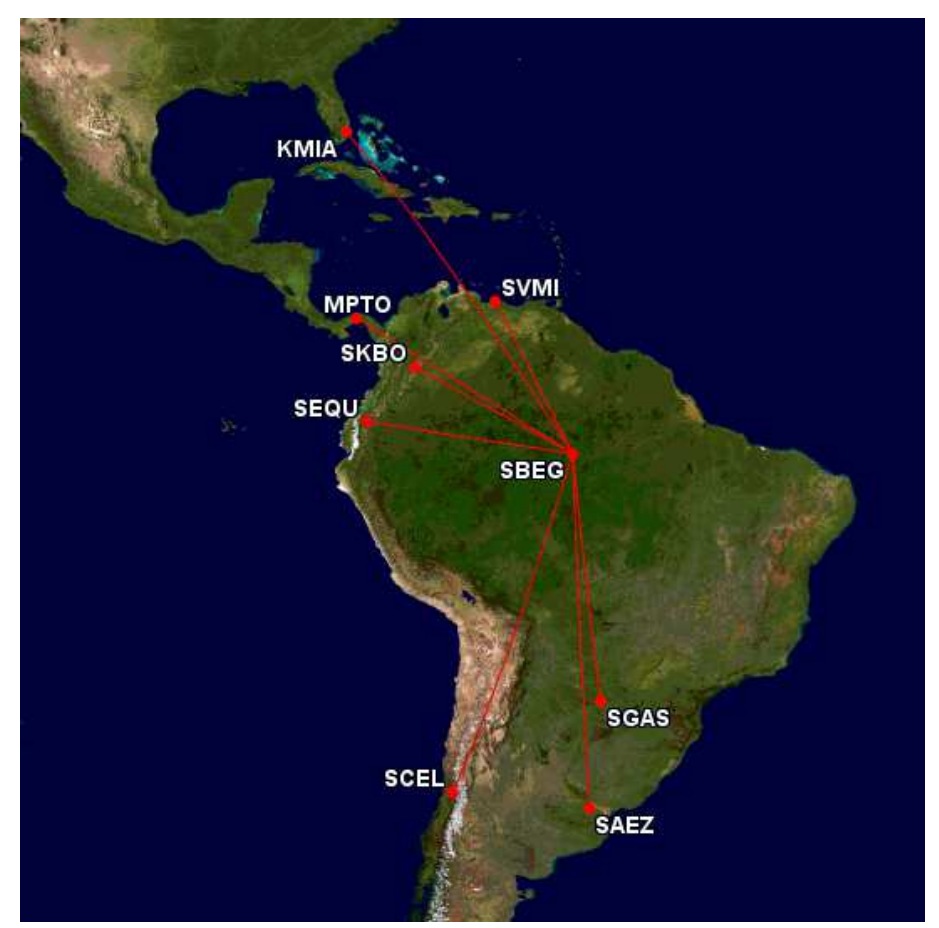

Figura 2 - Malha Aérea internacional. Fonte: ANAC

As conexões diretas internacionais ocorrem com Miami (KMIA), Panamá City (MPTO), Caracas (SVMI), Quito (SEQU), Bogotá (SKBO), Assunção (SGAS), Buenos Aires (SAEZ) e Santiago (SCEL). Desses destinos, apenas a cidade do Panamá e Miami são operadas para o transporte de passageiros, sendo todos os outros voos dedicados ao transporte de mercadorias.

Os voos no plano doméstico são apresentados na figura 3. Há voos diretos para Boa Vista (SBBV), Porto Velho (SBPV), Santarém (SBSN), Belém (SBBE), Fortaleza (SBFZ), Brasília (SBBR), Belo Horizonte (SBCF), Guarulhos (SBGR), Campinas (SBKP) e Rio de Janeiro (SBGL). 


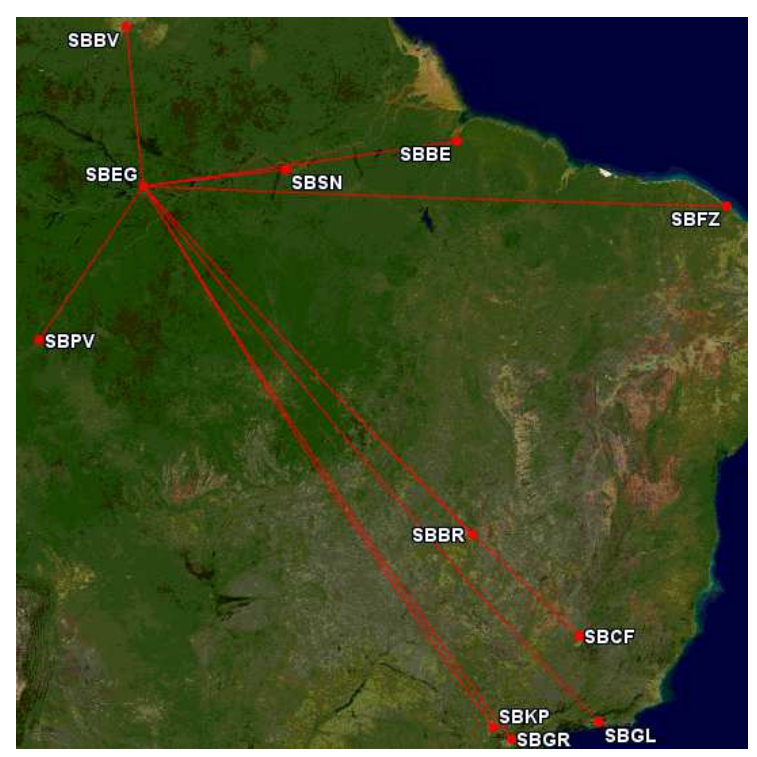

Figura 3 - Malha aérea doméstica do aeroporto. Fonte: ANAC

Por fim, a malha aérea regional do aeroporto de Manaus é apresentada na figura 4. Há conexões com as cidades de Porto de Trombetas (SBTB), Parintins (SWPI), Coari (SWKO), Humaitá (SWHT), Barcelos (SWBC), Tabatinga (SBTT) e Tefé (SBTF) e Santa Isabel do Rio negro (SWTP). Além disso, as cidades de Porto Velho (SBPV), Belém (SBBE) e Santarém (SBSN) também aparecem no rol dos destinos regionais da ANAC, embora já tivessem aparecido anteriormente como um destino da malha nacional.

Todas as conexões regionais são operadas por uma única empresa aérea: a TRIP. Esta situação de monopólio pode trazer consequências ao usuário do transporte aéreo, consequências estas desde o aumento abusivo do preço da passagem aérea bem como a saída da empresa dessa rota, portanto, requer o acompanhamento atento do órgão regulador.

No tocante ao turismo da região, depois da cidade de Manaus, $40 \%$ dos turistas internacionais costumam visitar a cidade de Presidente Figueiredo. Em segundo lugar com 20\% dos turistas fica Parintins, além de Novo Airão que atrai em torno de $13 \%$ de turistas estrangeiros. Os turistas domésticos também procuram Presidente Figueiredo e Parintins, 37\% e 23,4\% respectivamente. Vale ressaltar que destes três principais destinos turísticos o único que tem acesso via aérea, atualmente, é Parintins, os outros apesar de estarem a uma distância de um pouco mais de $105 \mathrm{~km}$ do aeroporto Eduardo Gomes, não são contemplados com voos regulares. 
A Fecomércio acredita que esses destinos, acima citados, atraem mais turistas principalmente por conta dos eventos que são realizados nestas cidades. Em Presidente Figueiredo, por exemplo, além de ser conhecida por ser "a terra das cachoeiras", ela realiza grandes eventos como a Festa do Cupuaçu. Parintins, também, é um destino bastante conhecido principalmente por conta da Festa do Boi, uma das mais importantes manifestações da cultura popular do Brasil que hoje é um espetáculo grandioso em porte, arte e técnica.

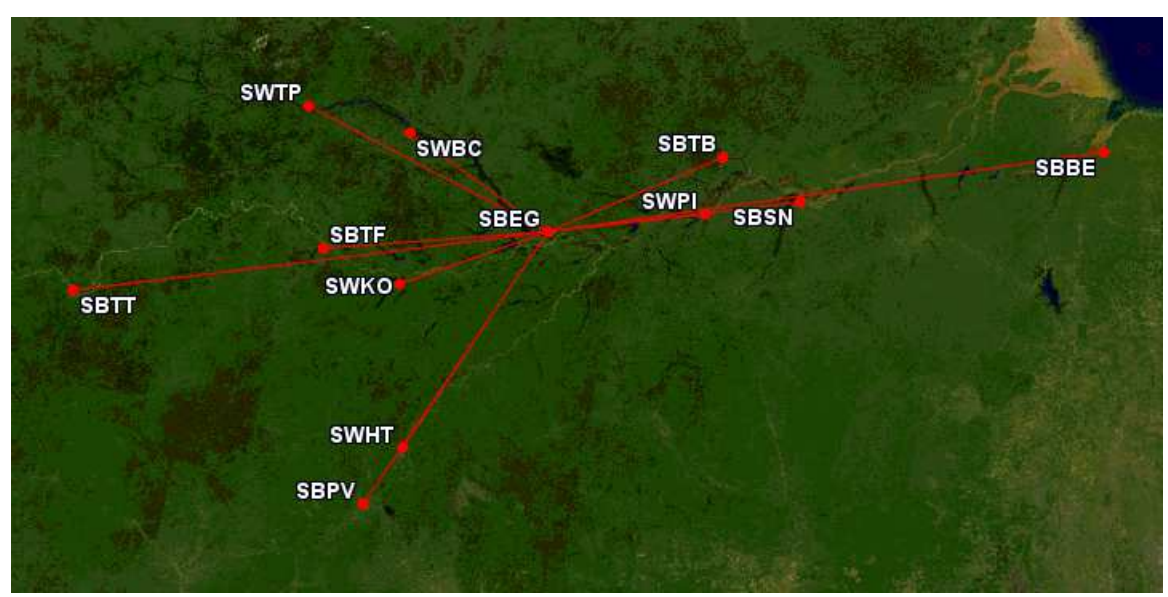

Figura 4 - Malha aérea regional do aeroporto de Manaus. Fonte: ANAC

O trânsito aéreo entre Manaus e qualquer outra cidade que não pertença a uma das três malhas apresentadas anteriormente, exigirá um voo com escalas ou conexões. Considerando a riqueza da cidade e o fato de ser a principal metrópole da região amazônica, talvez num futuro próximo se perceba a necessidade de que a cidade tenha mais voos diretos com outras localidades. O estado do Acre é um bom exemplo de uma região que poderia ter uma ligação aérea direta com Manaus.

Ao comparar a malha aérea das três principais operadoras de transporte de passageiros, observa-se que as companhias TAM e GOL possuem absolutamente a mesma malha aérea doméstica, com diferenças apenas no número de vezes que cada ligação ocorre semanalmente. A única diferença entre as duas se dá no cenário internacional, onde há uma ligação diária da TAM entre Manaus e Miami. Já a TRIP, opera apenas no âmbito regional, dominando completamente este segmento de operações. 


\section{Estudo de demanda pelo aeroporto}

Nesta seção será apresentada a base de dados considerada no modelo. Posteriormente será desenvolvido o modelo econométrico e, por fim, os resultados serão apresentados e analisados, explicando a previsão de demanda para 2014.

\subsection{Apresentação da base de dados}

A base de dados considerada foi retirada do site da Infraero (2010). Os dados considerados foram: a movimentação de passageiros no aeroporto Eduardo Gomes para os segmentos doméstico e internacional, o yield médio doméstico nominal, PIB nominal em reais, taxa de inflação (IPCA) e taxa de câmbio real-dólar nominal. Abaixo será explicado com mais detalhes as séries que foram consideradas.

Movimentação de Passageiros: são dados fornecidos pela INFRAERO. A série fornece medições mensais realizadas entre janeiro de 2003 e dezembro de 2010. Esses números serão correlacionados com alguns fatores que se supõe serem determinantes na formação da demanda.

Yield: valor médio pago por passageiro em cada quilômetro voado. Esses dados são medidos pela ANAC e deflacionados pelo índice de preços ao consumidor amplo- IPCA. Embora fosse preferível ter dados específicos sobre os voos com origem ou destino em Manaus, foi utilizada uma média nacional para o estudo, já que era a única opção disponível.

Produto interno bruto (PIB): esse índice é fornecido de forma nominal pelo Banco Central do Brasil. Os valores coletados são nominais e, portanto, foram deflacionados pelo IPCA e mantidos com base em janeiro de 2003. Mais uma vez seria preferível ter os dados referentes a Manaus somente, mas esses não estão disponíveis com periodicidade mensal, nem até o ano de 2009, como os demais dados da série.

Foi considerada também a taxa de câmbio para verificar a correlação entre essa variável e o movimento internacional de passageiros e de carga. Esses dados são fornecidos pelo Banco Central do Brasil. 
Através da Tabela 1, pode-se notar que o movimento médio de passageiros no aeroporto Eduardo Gomes é de $95 \%$ para voos domésticos e $5 \%$ para voos internacionais, evidenciando uma atuação essencialmente doméstica.

Tabela 1- Estatísticas descritivas das variáveis consideradas

\begin{tabular}{lccccc}
\hline Variáveis & Obs & Média & Desvio Padrão & Min & Max \\
\hline paxdom & 84 & 138323.30 & 35646.67 & 57158.00 & 244729.00 \\
paxint & 84 & 6841.39 & 4336.11 & 1456.00 & 21397.00 \\
PIB & 84 & 235137.30 & 27970.35 & 185329.20 & 293592.70 \\
yield & 84 & 0.65 & 0.14 & 0.38 & 0.84 \\
usd & 84 & 2.84 & 0.89 & 1.70 & 5.19 \\
\hline
\end{tabular}

Por fim, foram introduzidas as variáveis binárias dcshare, dapagao e dcrise para controlar os efeitos dos eventos de codeshare entre as empresas Varig e TAM de 2003 a 2005, do apagão aéreo em 2006 e 2007, e da crise mundial em julho de 2008 e dezembro de 2009, respectivamente, bem como variáveis temporais do tipo mês para controlar a sazonalidade.

Na Tabela 2, verifica-se o efeito do apagão aéreo na movimentação de passageiros, tanto doméstica quanto internacional. Observa-se que houve um ligeiro aumento na movimentação de passageiros tanto internacionais quanto domésticos.

Tabela 2- Efeito do apagão aéreo de 2006/2007 no movimento de passageiros e no yield dapagao $=0$

\begin{tabular}{lccccc}
\hline Variáveis & Obs & Média & Desvio Padrão & Min & Max \\
\hline \multicolumn{7}{c}{$\begin{array}{l}\text { Maxdom } \\
\text { paxint }\end{array}$} & 74 & 136443.40 & 37069.82 & 57158.00 & 244729.00 \\
yield & 74 & 6661.42 & 4535.81 & 1456.00 & 21397.00 \\
dapagao=1 & .68 & .1229561 & .42 & .84 \\
\hline \multicolumn{7}{c}{} \\
\hline Variáveis & Obs & Média & Desvio Padrão & Min & Max \\
\hline \multicolumn{7}{c}{} \\
\hline paxdom & 10 & 152234.10 & 18122.27 & 132157.00 & 189136.00 \\
paxint & 10 & 8173.20 & 2069.44 & 5653.00 & 12262.00 \\
yield & 10 & .48 & .11 & .38 & .73 \\
\hline
\end{tabular}


Na Tabela 3, confirma-se o efeito do codeshare Varig-TAM no período de 2003 a 2005, tanto no yield quanto no paxdom. Há uma redução do preço das passagens aéreas (yield) com o fim do codeshare e o início da guerra de preços e, por conseguinte, há um aumento considerável na demanda, confirmada pelo aumento do movimento doméstico de passageiros.

Tabela 3- Efeito do codeshare Varig-TAM (2003 a 2005) no movimento doméstico e no yield

\begin{tabular}{|c|c|c|c|c|c|}
\hline Variáveis & Obs & Média & Desvio Padrão & Min & Max \\
\hline paxdom & 58 & 152368.90 & 33462.44 & 57158.00 & 244729.00 \\
\hline yield & 58 & .60 & .13 & .38 & .84 \\
\hline \multicolumn{6}{|l|}{ dcshare $=1$} \\
\hline Variáveis & Obs & Média & Desvio Padrão & Min & Max \\
\hline paxdom & 26 & 106990.60 & 13674.22 & 82870.00 & 134126.00 \\
\hline yield & 26 & .77 & .05 & .66 & .83 \\
\hline
\end{tabular}

$\mathrm{Na}$ Tabela 4, verifica-se o efeito da crise econômica mundial na movimentação de passageiros. Diferentemente do esperado, para o caso dos passageiros internacionais observase que a crise não influenciou a demanda neste segmento, e que houve um ligeiro aumento na movimentação de passageiros durante esse período. Para a movimentação doméstica, como a crise não afetou a economia brasileira, percebe-se que também não afetou os passageiros domésticos desse aeroporto.

Tabela 4- Efeito da crise econômica mundial de 2008/2009 no movimento de passageiros e no yield dcrise $=0$

\begin{tabular}{lccccc}
\hline Variáveis & Obs & Média & Desvio Padrão & Min & Max \\
\hline \multicolumn{7}{c}{} & & & & & \\
\hline paxdom & 78 & 142178.80 & 40734.45 & 82870.00 & 243040.00 \\
paxint & 78 & 6712.63 & 4579.73 & 1456.00 & 21397.00 \\
Yield & 78 & .69 & .18 & .34 & .91 \\
\hline
\end{tabular}


dcrise $=1$

\begin{tabular}{lccccc}
\hline Variáveis & Obs & Média & Desvio Padrão & Min & Max \\
\hline & & & & & \\
\hline paxdom & 18 & 169900.20 & 25691.24 & 135940.00 & 217758.00 \\
paxint & 18 & 11706.44 & 2163.13 & 8305.00 & 17 \\
Yield & 18 & .58 & .12 & .45 & .91 \\
\hline
\end{tabular}

Fazendo uma análise das correlações entre variáveis conforme tabela 5. Observa-se que o movimento doméstico de passageiros bem como o movimento internacional é negativamente correlacionado com o yield, com a taxa de câmbio e com o codeshare, porém positivamente correlacionado com o PIB, com o período do apagão e com o período de crise.

Tabela 5 - Matriz de correlações

\begin{tabular}{l|cccccccc}
\hline & paxdom & paxint & usd & PIB & yield & dapagao deshare & dcrise \\
\hline & & & & & & & & \\
paxdom & 1.0000 & & & & & & & \\
paxint & 0.7835 & 1.0000 & & & & & & \\
usd & -0.8042 & -0.7341 & 1.0000 & & & & & \\
PIB & 0.8698 & 0.7845 & -0.8795 & 1.0000 & & & & \\
yield & -0.7490 & -0.6765 & 0.6802 & -0.7499 & 1.0000 & & & \\
dapagao & 0.0419 & 0.0386 & -0.1255 & 0.0214 & -0.2868 & 1.0000 & & \\
dcshare & -0.6222 & -0.6357 & 0.7828 & -0.6536 & 0.5694 & -0.2078 & 1.0000 & \\
dcrise & 0.2735 & 0.4208 & -0.3404 & 0.4031 & -0.2389 & -0.1638 & -0.2928 & 1.0000 \\
\hline
\end{tabular}

\subsection{Estudo econométrico e análise de resultados}

As análises foram feitas para dois cenários diferentes que envolvem as combinações de tráfego de passageiros nas modalidades doméstico e internacional. A primeira análise contemplou o estudo de passageiros domésticos. Neste segmento foram consideradas como sendo de interesse as variáveis PIB, yield médio e as dummies de apagão aéreo, codeshare e sazonalidade mensal. A regressão foi feita para os dois tipos de modelo, tanto o linear quanto o logarítmico, os resultados dos mesmos podem ser visto na tabela 6 . 
Tabela 6- Resultados dos modelos, linear e logarítmico, de regressão para número de passageiros domésticos.

\begin{tabular}{|c|c|c|}
\hline Variable & 1inear & log_1og \\
\hline $\begin{array}{r}\text { gdp } \\
\text { yield } \\
\text { 1ngdp } \\
\text { 1nyield } \\
\text { dcshare } \\
\text { dapagao } \\
\text { m_2 } \\
\text { m_3 } \\
\text { m_4 } \\
\text { m_5 } \\
\text { m_6 } \\
\text { m_7 } \\
\text { m_8 } \\
\text { m_9 } \\
\text { m_10 } \\
\text { m_11 } \\
\text { m_12 }\end{array}$ & $\begin{array}{l}.664^{* * *} \\
-67667^{* * *} \\
-3470 \\
-9746 \\
-20758^{* * *} \\
-41483^{* * *} \\
-36774^{* * *} \\
-42821^{* * *} \\
-40270^{* * *} \\
-11190^{*} \\
-31942^{* * *} \\
-34922^{* * *} \\
-28735^{* * *} \\
-36168^{* * *} \\
-4379^{2}\end{array}$ & $\begin{array}{l}1.23^{* * *} \\
-.219^{* *} \\
-.0576^{*} \\
-.0375 \\
-.13^{* * *} \\
-.271^{* * *} \\
-.247^{* * *} \\
-.292^{* * *} \\
-.273^{* * *} \\
-.0775^{* *} \\
-.21^{* * *} \\
-.234^{* * *} \\
-.202^{* * *} \\
-.245^{* * *} \\
-.0413\end{array}$ \\
\hline r2_a & .894 & .903 \\
\hline
\end{tabular}

Os parâmetros com melhor significância estatística são aqueles cujos valores das estatísticas t são elevados e onde os p-valor são baixos, o que permite excluir a hipótese de influência nula da variável. Ao comparar os dois modelos, verifica-se que as variáveis independentes PIB e yield, bem como as variáveis binárias de sazonalidade possuem uma significância considerável nos dois casos. No entanto a variável que define o apagão aéreo parece não ter grande significância para $o$ aeroporto em questão. A variável binária que representa o codeshare Varig-TAM, apresenta uma melhor significância estatística no modelo logarítmico.

Para extrair a elasticidade do número de passageiros em relação às variáveis investigadas, utiliza-se o modelo logarítmico. Observa-se que a elasticidade medida em relação ao PIB é de 1,23 isso signfica que a cada aumento do PIB em um 1\% a demanda de passageiros aumenta em $23 \%$ enquanto que em relação ao Yield é de - 0,219 , ou seja, com o aumento do yield em $1 \%$ a demanda de passageiros diminui de $0,219 \%$.

O mesmo procedimento foi adotado para o tráfego internacional de passageiros. Neste caso a variável do câmbio e a variável binária referente à crise econômica foram adicionadas por serem consideradas como prováveis fatores de influência na decisão das pessoas em viajar para o exterior. 
Tabela 7 - Resultados dos modelos, linear e logarítmico, de regressão para número de passageiros internacionais.

\begin{tabular}{|c|c|c|c|c|c|}
\hline Variable & Logint_1 & Logint_2 & Linint_3 & Linint_4 & Linint_5 \\
\hline $\begin{array}{r}\text { gdp } \\
\text { usd } \\
\text { 7ngdp } \\
\text { Inusd } \\
\text { dcrise } \\
\text { dapagao } \\
\text { m_2 } \\
\text { m_3 } \\
\text { m_4 } \\
\text { m_5 } \\
\text { m_6 } \\
\text { m_7 } \\
\text { m_8 } \\
\text { m_-9 } \\
\text { m_10 } \\
\text { m_11 } \\
\text { m_12 }\end{array}$ & $\begin{array}{l}3.93^{* * *} \\
-.263^{2} \\
.189^{* *} \\
-.159 \\
-.414^{* *} \\
-.528^{* * *} \\
-.867^{* * *} \\
-.63^{* * *} \\
-.32^{2} \\
-.62^{* * *} \\
-.47^{*} \\
-.752^{* * *} \\
-.825^{* * *} \\
-.627^{*} * *\end{array}$ & $\begin{array}{l}3.4^{* * *} \\
-.376^{*} \\
-239^{* *} \\
.238^{* * *} \\
-.184^{*} \\
-.413^{* *} \\
-.527^{* * *} \\
-.844^{* * *} \\
-.605^{* * *} \\
-.331^{*} \\
-.617^{* * *} \\
-.474^{*} \\
-.741^{* * *} \\
-.807^{* * *} \\
-.616^{* * *}\end{array}$ & $\begin{array}{l}.0686^{* * *} \\
-890 \\
\\
1580^{*} \\
370\end{array}$ & $\begin{array}{l}.0978^{* * *} \\
-90.8 \\
\\
1336 \\
640 \\
-1210^{*} \\
-2508^{* *} \\
-2823^{* * *} \\
-5092^{* * *} \\
-3793^{* * *} \\
-1603 \\
-3368^{* * *} \\
-1963 \\
-4512^{* * *} \\
-5035^{* * *} \\
-3953^{* * *}\end{array}$ & $\begin{array}{l}353 \\
-1149 * \\
-2521^{* *} \\
-2845^{* * *} \\
-5182^{* * *} \\
-3897^{* * *} \\
-1529 \\
-3353^{* * *} \\
-1928 \\
-4508^{* * *} \\
-5050^{* * *} \\
-3945^{* * *}\end{array}$ \\
\hline r2_a & .719 & .73 & .622 & .684 & .676 \\
\hline
\end{tabular}

Para os passageiros internacionais, o PIB possui uma grande significância. Como mostrado na tabela 7, isso acontece principalmente, pois, com o aumento do poder aquisitivo, ocasionado indiretamente pelo PIB, as pessoas tendem a viajar mais para o exterior. A variável da taxa de câmbio, não apresenta uma boa significância para o modelo, isso pode ser explicado pelo fato de que o aumento no câmbio pode favorecer a vinda de estrangeiros e dificultar a saída de brasileiros rumo ao exterior, havendo, portanto uma provável anulação da significância para os passageiros internacionais em geral. Como a malha aérea internacional de passageiros é bastante reduzida, uma eventual omissão de variáveis relevantes (como a adição ou cancelamento de uma rota ocorrido nos últimos anos), pode ter um efeito significativo sobre o movimento de passageiros.

As variáveis binárias que representam os períodos de crise e do apagão aéreo são significantes, porém ambas tem o sinal positivo no coeficiente, o que significa uma relação diretamente proporcional com a demanda de passageiros internacionais. Pode considerar que este é um fato, no mínimo curioso, em períodos de crise e de apagão aéreo a demanda por transporte aéreo internacional não sofreu uma diminuição, muito pelo contrário, ela aumentou, talvez um pouco menos do que ela poderia ter crescido se não houvesse a crise e o apagão aéreo.

Ao fazer a regressão com os logaritmos, considerando o modelo com maior p-valor (Logint_2) foi obtida uma elasticidade de 3,4 em relação ao PIB e -0,376 em relação ao 
câmbio mas com uma baixa significância. Nesse caso, acredita-se que o modelo Logint_2 pode ser considerado o modelo mais representativo da demanda internacional pelo aeroporto Eduardo Gomes.

\subsection{Previsão de demanda}

Os modelos apresentados acima permitem calcular a demanda futura do aeroporto de Manaus. Para a demanda doméstica o modelo escolhido foi o modelo linear. Foi considerado um crescimento do PIB de 4,5\% ao ano a partir de 2010. O yield considerado para todos os períodos futuros foi igual ao yield no mês de dezembro de 2010. Outras hipóteses consideradas são que não haverá um novo período de apagão aéreo nem de crise econômica.

O movimento doméstico de passageiros deverá crescer a uma taxa de 5,2\% ao ano entre 2010 e 2014, sem considerar os efeitos da copa do mundo no ano de 2014. Em 2014 a demanda de passageiros doméstico no aeroporto de Manaus será de 3,52 milhões anual. Esse valor, que ainda exclui os movimentos internacionais, já está bem acima da capacidade atual de 2,5 milhões de movimentos por ano.

A previsão para movimentos internacionais foi realizada de forma semelhante, e o modelo considerado campeão nesse caso, também foi o modelo linear. Porém, diferentemente dos passageiros domésticos, o modelo para demanda internacional ainda é considerado bastante frágil, visto o contexto neste aeroporto, que possui um número bem reduzido de voos internacionais. É provável que o principal fator de influência seja a adição ou o cancelamento de rotas. Nesse modelo, considerou-se que a taxa de câmbio do dólar é constante em 1,756 nos próximos anos, além de um crescimento do PIB de 4,5\% ao ano a partir de 2010. Com isso, a demanda prevista é de 295 mil passageiros internacionais em 2014, ou seja, um crescimento composto de $15 \%$ ao ano.

Ao se analisar as taxas de crescimento da demanda doméstica e internacional percebe-se que existe uma diferença considerável entre as duas. Uma explicação para essa diferença pode ser o fato de que na demanda doméstica foi considerado o yield constante para os próximos quatro anos, e como visto anteriormente o yield (tabela 6) é bastante significativo para a demanda. Outro fator que deve ser considerado é que foi utilizada uma taxa de câmbio constante para a demanda internacional., A variável PIB, se mostrou bastante significante, 
acredita-se que é por isso que a demanda internacional teve taxas tão elevadas, ou seja, com uma alta significância do PIB frente a demanda internacional.O aumento de 4,5\% ao ano do PIB pode representar um aumento ainda maior na demanda internacional, como o modelo previu.

De posse do resultado para a demanda de passageiros internacionais e, com a ciência de que, segundo dados do Estudo da Demanda Turística (2010), cerca de 20\% dos passageiros que chegam em Manaus tem como motivo de viagem o lazer e que, conforme o Anuário do Ministério do Turismo (2011), o modal aéreo representa mais de 93\% dos turistas que chegam no estado do Amazonas. Verifica-se com esses dados a existência de um crescimento do setor de quase $15 \%$ ao ano até 2014, chegando, portanto em 2014, a um total de 59 mil turistas, mais que duplicando a quantidade de turistas que existe atualmente.

\section{Conclusões}

Sabe-se que atualmente assuntos relacionados ao setor aéreo brasileiro tem grande destaque nas discussões da mídia e do governo no âmbito nacional. $\mathrm{O}$ objetivo desse trabalho foi fazer uma projeção da demanda, doméstica e internacional, para 2014, no aeroporto Internacional Eduardo Gomes em Manaus, bem como analisar a influência desta para o setor de turismo. Para o modelo de passageiros domésticos, as variáveis com uma melhor significância são o PIB e o yield, todos com significância estatística a 1\%. A demanda projetada de passageiros domésticos para o ano de 2014 é de 3,52 milhões de passageiros transportados. Percebe-se que, com esse aumento na demanda de passageiros, se nada for feito, o aeroporto de Manaus, que atualmente tem uma capacidade de 2,5 milhões de passageiros ano, já estaria saturado. $\mathrm{O}$ aeroporto de Manaus só conseguirá suportar o aumento da demanda se houver investimentos na sua infraestrutura para aumentar a sua capacidade de operação.

No caso dos passageiros internacionais foi adicionada a variável do câmbio por ser um fator de forte influência na decisão das pessoas em viajar para o exterior. Para os passageiros internacionais a variável PIB tem uma alta significância. As outras variáveis, entre elas o câmbio, apresentam um p-valor relativamente alto. Sendo assim, acredita-se que as mesmas não tem uma grande significância para o aeroporto Eduardo Gomes. Alguns fatores podem explicar a falta de significância dessas variáveis. Primeiramente, o fato do aeroporto de 
Manaus ter apenas dois destinos internacionais e, como a malha aérea internacional de passageiros é bastante reduzida, uma eventual mudança que tenha ocorrido nos últimos anos, como a adição ou cancelamento de uma rota, pode ter tido um efeito mais significativo sobre o movimento de passageiros do que as variáveis que foram consideradas.

A previsão de demanda de passageiros internacional será, em 2014, um pouco mais de 295 mil passageiros, totalizando 3,8 milhões de passageiros para 2014. Isso confirma a necessidade de investimentos na infraestrutura para que o aeroporto possa atender a demanda futura. Se concretizada a obra de aumento da capacidade de 2,5 para 5 milhões passageiros até 2014 o aeroporto de Manaus deverá atender a demanda prevista. Vale ressaltar, portanto, que se a demanda continuar crescendo a taxa de 5,2\% a.a., em 2020 o aeroporto Eduardo Gomes já estará operando acima da sua capacidade.

O modal aéreo é reponsável por 93\% dos turistas que chegam no estado do Amazonas e nas rotas de voos internacionais cerca de $20 \%$ dos passageiros vem a Manaus para fazer turismo. Considerando que o crescimento do setor turístico tenha o crescimento equivalente ao crescimento da demanda aeroportuária pelo Eduardo Gomes o turismo crescerá a uma taxa de 15\% ao ano até 2014. Caso isso aconteça, o turismo da região chegará em 2014 com uma demanda anual de 59 mil turistas, mais que duplicando a quantidade de turistas que existe atualmente.

Vale ressaltar que a simples criação de uma rota direta entre Manaus e Europa, poderia quase duplicar o fluxo de turista no estado. Isso pode ser concluido ao analisar os dados do Estudo da Demanda Turística (2010), onde verifica-se que há uma demanda, pelo estado do Amazonas, de quase $34 \%$ de estrangeiros cujo país de residência se situa na Europa. Isso demonstra a grande potencialidade que o estado do Amazonas tem para o turismo. É necessário salientar que o setor do turismo representa hoje 2,1\% do PIB do Amazonas, uma participação considerável que merece uma maior atenção por parte dos governantes. Até porque o turismo também é considerado como um motor para o desenvolvimento regional de um estado, desenvolvimento esse de suma importância para a realidade do Norte do Brasil. 


\section{Referências}

ANAC (2011). HOTRAN. Agência Nacional de Aviação Civil, Ministério da Defesa, Brasília, DF.

Branco, J. E. H. e Caixeta Filho, J. V. (2011) Estimativa da demanda de carga captável pela estrada de ferro Norte-Sul. Journal of Transport Literature, vol. 5, n. 4, pp. 17-50.

Condé, M. (2011) Estudo e previsão de demanda aeroportuária para a cidade do Rio de Janeiro. Journal of Transport Literature, vol. 5, n. 1, pp. 161-183.

Correia, A. R., Niyama, L. E. e Nogueira, S. A. F. (2011) Estimativa da distribuição da demanda na região metropolitana de São Paulo com cenários de um novo aeroporto. Journal of Transport Literature, vol. 5, n. 2, pp. 44-62.

Diniz, R. R. (2013) Dimensionamento de ampliação do aeroporto de Marabá com base em estudo de previsão de demanda aeroportuária. Journal of Transport Literature, Vol. 7, n.1.

Infraero (2011). http://www.infraero.gov.br/index.php/br/aeroportos/amazonas/aeroportointernacional-eduardo-gomes.html. Site da Empresa Brasileira de Infraestrutura Aeroportuária, Ministério da Defesa, Brasília, DF.Acessado em 13/05/2011.

Relatório Consolidado (2010) Estudo do Setor de Transporte Aéreo do Brasil: Relatório Consolidado. Rio de Janeiro: McKinsey \& Company, 2010.380p

Rocha, G. C. (2010) Ensaios sobre a Demanda do Transporte Aéreo Regional. Journal of Transport Literature, vol. 4, n. 1, pp. 114-133.

IBGE (2011). Site do Instituto brasileiro de geografia e estatística. Censo 2010. Acessado em 13/05/2011.

Jornal Brasil (2011) http://www.jornalbrasil.com.br/interna.php?autonum=23469. Site do Jornal Brasil.Acessado em 13/05/2011.

Infoescola (2011) http://www.infoescola.com/economia/zona-franca-de-manaus/ Site acessado em $28 / 06 / 2011$.

Neleman, S. M. C. (2009) O ecoturismo na amazônia brasileira: panacéia ou cavalo de Tróia para a comunidade ribeirinha? Tese de mestrado. Línguas e culturas da América Latina. Universidade de Leiden Junho, 2009.

Bessa, A. K. O. e Batista, S. P. M. (2010) Aeroporto internacional Eduardo Gomes: perspectiva para 2014. Revista Eletrônica Aboré - Publicação da Escola Superior de Artes e Turismo Manaus Edição 04 Dez/2010 ISSN 1980-6930. 11p

Ministério do Turismo (2011). Anuário Estatístico de Turismo - 2011. Publicado pela Secretaria Nacional de Políticas de Turismo. Volume 38. Ano base 2010

Estudo da demanda turística internacional 2004-2009 (2010). Departamento de Estudos e Pesquisas. Secretária Nacional de Políticas de Turismo. Ministério do Turismo. Brasília, novembro de 2010.

Santos, F. A. B. (2008) Demanda por Transporte Aéreo e seus Desdobramentos. Journal of Transport Literature, vol. 2, n. 2, pp. 94-113.

International Ecotourism Society (2011). Site do International Ecotourism Society acessado em 09 de julho de 2011. http://www.ecotourism.org/site/c.orLQKXPCLmF/b.4835303/k.BEB9/ What_is_Ecotourism_The_International_Ecotourism_Society.htm 